\title{
CO electrooxidation on Sn-modified Pt single crystals in acid media弦
}

\author{
Ruben Rizo ${ }^{a}$, Elena Pastor ${ }^{\mathrm{a}}$, Marc T.M. Koper ${ }^{\mathrm{b}, *}$ \\ a Departamento de Química Física, Instituto de Materiales y Nanotecnología, Universidad de La Laguna, Apdo. 456, 38206 La Laguna, Santa Cruz de Tenerife, Spain \\ b Leiden Institute of Chemistry, Leiden University, PO Box 9502, 2300 RA Leiden, The Netherlands
}

\section{A R T I C L E I N F O}

Article history:

Received 19 July 2016

Received in revised form 26 September 2016

Accepted 7 October 2016

Available online 11 October 2016

\section{Keywords:}

Carbon monoxide oxidation

Platinum-tin electrodes

Bifunctional mechanism

Electrocatalysis

\begin{abstract}
A B S T R A C T
The irreversible adsorption of Sn on the three Pt basal planes (Sn/Pt(111), Sn/Pt(100) and Sn/Pt(110)) and the oxidation of adsorbed carbon monoxide have been studied by cyclic and stripping voltammetry. The presence of $\mathrm{Sn}$ adatoms blocks the adsorption of hydrogen on platinum, and leads to the observation of a new oxidation peak ascribed to the four-electron oxidation of the $\mathrm{Sn}$ adatom at potentials above $0.5 \mathrm{~V}$. The oxidation of adsorbed carbon monoxide is enhanced by the presence of $\mathrm{Sn}$ on all three Pt single crystals. On Sn/Pt(111) and Sn/Pt(110), oxidation of adsorbed $\mathrm{CO}$ occurs in two distinct potential regions: a pre-peak region at potentials below $0.50 \mathrm{~V}$ and the main peak at higher potentials. In the pre-peak, the oxidation of adsorbed $\mathrm{CO}$ is suggested to take place at the direct interface between Pt and Sn through the formation of an activated water species on Sn that is not observable in the blank voltammetry. In the main peak, the $\mathrm{CO}_{\text {ad }}$ oxidation reaction is suggested to occur through the classical bifunctional mechanism of $\mathrm{OH}$ adsorbed on $\mathrm{Sn}$ with $\mathrm{CO}$ adsorbed on Pt atoms no adjacent to Sn atoms. On Sn/Pt(100), the "pre-peak mechanism" is not observed.
\end{abstract}

(c) 2016 Elsevier B.V. All rights reserved.

\section{Introduction}

Although Pt is very efficient for the oxidation of small organic molecules, there is general consensus that it is readily poisoned by even trace levels of carbon monoxide formed during the reaction [1]. Many studies have demonstrated that the combination of Pt with Sn modifies the electronic and chemical properties so as to improve the catalytic properties of Pt [2-10]. Moreover, it is now well stablished that the Pt surface structure greatly influences the CO oxidation reaction [11-29]. Adatom modified Pt single crystals surfaces have been studied extensively, mainly focused on the enhancement in the rates of $\mathrm{CO}$ oxidation [3041]. A bifunctional mechanism was put forward to explain faster rates for $\mathrm{CO}$ oxidation on Pt single crystals modified by p-block elements (i.e., Bi, As, Sb, Sn). More specifically, a detailed understanding of the promotional effect of Sn remains a subject of conflicting results and debate. Hayden et al. [37] and Stamenkovic et al. [38,39] investigated the $\mathrm{CO}$ oxidation on well-defined (surface) alloy $\mathrm{Pt}_{3} \mathrm{Sn}$ (111) electrodes prepared in Ultra High Vacuum (UHV). Hayden et al. presented evidence for the classical bifunctional mechanism of CO oxidation on PtSn by showing the formation of $\mathrm{OH}$ on the Sn sites at low potential $(0.25 \mathrm{~V}$ vs. RHE), and CO oxidative stripping coincident with the adsorption of

\footnotetext{
is Dedicated to Professor Masatoshi Osawa on the occasion of his retirement from the Institute of Catalysis of Hokkaido University and in recognition to his seminal contributions to physical electrochemistry.

* Corresponding author.

E-mail address: m.koper@chem.leidenuniv.nl (M.T.M. Koper).
}

$\mathrm{OH}$ on the Sn sites. Stamenkovic et al. [38] found by FTIR that, in contrast to the near invariant band of linearly bonded $\mathrm{CO}_{\mathrm{ad}}$ on $\mathrm{Pt}(111)$, a splitting of the band and a corresponding change in frequency takes place for $\mathrm{CO}_{\mathrm{ad}}$ on the $\mathrm{Pt}_{3} \mathrm{Sn}$ (111) alloy. They suggested that the high-frequency $\mathrm{CO}_{\mathrm{ad}}$ is a weakly adsorbed $\mathrm{CO}$ occupying Pt atoms which are adjacent to "OH $\mathrm{OH}_{\mathrm{ad}}$ "-covered Sn atoms. In subsequent work, Stamenkovic et al. studied the $\mathrm{CO}$ oxidation on a $\mathrm{Pt}_{3} \mathrm{Sn}(110)$ alloy and compared the results with those obtained on the $\mathrm{Pt}_{3} \mathrm{Sn}(111)$ one [39]. For the $\mathrm{Pt}_{3} \mathrm{Sn}(110)$ surface neither the splitting nor the "high-frequency" $\mathrm{CO}_{\mathrm{ad}}$ band was found by FTIR. In terms of activity for the oxidation of adsorbed $\mathrm{CO}$, they found that a continuous oxidative removal of adsorbed $\mathrm{CO}$ starts at potentials as low as $\mathrm{E}=0.1 \mathrm{~V}$ on both $\mathrm{Pt}_{3} \mathrm{Sn}$ surfaces, which is an important property for CO-tolerant catalysts. Well-defined PtSn surfaces can also be prepared by electrochemical deposition of Sn on Pt single-crystal electrodes. Massong et al. [40] modified the Pt (111) surface using Sn underpotential deposition (UPD), giving rise to a peak around $0.60 \mathrm{~V}$ (vs. RHE) ascribed to an adsorbed hydroxyl species, on which surface a significant decrease of the onset potential for $\mathrm{CO}$ oxidation was found in $\mathrm{H}_{2} \mathrm{SO}_{4}$ electrolyte. Zheng et al. [41] investigated the irreversible adsorption of $\mathrm{Sn}$ on the three Pt basal planes in sulfuric and perchloric acid media and found that $\mathrm{Sn}$ is adsorbed preferentially in the threefold hollow sites of Pt(111) surface and on the fourfold hollow sites of Pt(100), whereas no significantly irreversible adsorption was detected on the Pt(110) surface.

Although CO adsorption on Pt single crystals surfaces has been studied extensively, papers comparing the reactivity of Sn-modified Pt lowindex surfaces have not yet been published. In this work, the surface 
stoichiometry for the Sn surface reaction and the $\mathrm{CO}$ adlayer oxidation on $\mathrm{Sn} / \mathrm{Pt}(111), \mathrm{Sn} / \mathrm{Pt}(100)$ and $\mathrm{Sn} / \mathrm{Pt}(110)$ electrodes is studied for different Sn coverages using cyclic and stripping voltammetry. Our results suggest at least two different mechanisms through which Sn adatoms on the Pt surface can enhance the CO oxidation activity.

\section{Experimental}

Bead-type Pt single-crystal electrodes, prepared according to the Clavilier method, [42] have been used in this study. Prior to the experiments, the single crystal electrode was flame annealed and cooled down to room temperature in a hydrogen/argon atmosphere (1:3) and was transferred to the cell under the protection of a drop of ultra-pure water saturated with these gases. The experiments were carried out at room temperature in a classical three-electrode cell connected to an Autolab PGSTAT $302 \mathrm{~N}$ potentiostat. A platinum wire was used as a counter electrode and a reversible hydrogen electrode (RHE) in the supporting electrolyte as the reference electrode. All potentials in the text are referred to this electrode. The electrolyte employed was $0.1 \mathrm{M}$ $\mathrm{HClO}_{4}$ prepared from $\mathrm{HClO}_{4}$ (Merck p.a.) and ultra-pure water (Millipore MilliQ gradient A10 system, $18.2 \mathrm{M} \Omega \mathrm{cm}, 2 \mathrm{ppb}$ total organic carbon). The electrolyte was deaerated with pure $\operatorname{Ar}$ (N66, Air Liquide) to remove oxygen and $\mathrm{CO}$ (N47, Air Liquide) to dose CO. Voltammetric curves were obtained with the electrode in hanging meniscus configuration. The stability of the voltammetric profiles was carefully checked to ensure solution cleanliness and surface order. The CO stripping was studied by bubbling the gas in the bulk of the solution for $10 \mathrm{~min}$ while polarizing the electrode at $0.10 \mathrm{~V}$ followed by argon purging for 15 min to remove the excess CO. Next, the working electrode was brought back into the meniscus configuration and the oxidation of the $\mathrm{CO}$ adlayer was initiated by scanning the potential up to $0.90 \mathrm{~V}$ (vs. $\mathrm{RHE}$ ) at $20 \mathrm{mV} \mathrm{s}^{-1}$. The CO was introduced in the same cell in which the blank voltammograms for the Pt and Sn-covered Pt electrodes were recorded.

Deposition of Sn adatoms onto the Pt single crystals was carried out by immersion of the Pt single crystal, after flame-annealing process, into a solution containing $0.1 \mathrm{M} \mathrm{HClO}_{4}$ and $10 \mathrm{mM} \mathrm{Sn}^{2+}$ ions for different time spans (2-15 $\mathrm{min}$ ), depending on the coverage that we wanted to obtain. The resulting Sn coverage was calculated from the suppression of the hydrogen adsorption charge according to the following equation $[40,43]$ :

$\theta_{S n}=\left(Q_{P t}^{H}-Q_{P t, S n}^{H}\right) / Q_{P t}^{H}$

where $Q_{P t}^{H}$ and $Q_{P t, S n}^{H}$ are the charges for hydrogen adsorption in absence and presence of deposited Sn.

\section{Results and discussion}

\section{1. $\operatorname{Pt}(111)$}

Fig. 1a shows the stable voltammetric profiles in $0.1 \mathrm{M} \mathrm{HClO}_{4}$ obtained with $\mathrm{Pt}(111)$ and Sn/Pt(111) electrodes with different Sn coverage. On Pt(111) one observes the usual hydrogen adsorption region from 0.10 to $0.40 \mathrm{~V}$, and the $\mathrm{OH}$ adsorption region from 0.55 to $0.90 \mathrm{~V}$, characterized by a broad feature from $0.60 \mathrm{~V}$ and a sharp peak at $0.80 \mathrm{~V}$. Sn adsorption leads a change in the voltammetric profile depending on the Sn coverage. At lower Sn coverage a small decrease in the hydrogen adsorption charge can be observed as well as a decrease of the charge of the peak at $0.80 \mathrm{~V}$, while a new reversible peak arises at around $0.68 \mathrm{~V}$. For Sn coverages between ca. 0.45 and 0.80 , the adsorption of hydrogen is strongly inhibited and the initial peaks at 0.68 and $0.80 \mathrm{~V}$ evolve into two new peaks at 0.62 and $0.85 \mathrm{~V}$. The integrated charge for the peak at $0.62 \mathrm{~V}$ is around $1 / 3$ of the charge corresponding to the peak at $0.85 \mathrm{~V}$, which suggest an overall oxidation process from $\mathrm{Sn}$ to $\begin{array}{lllllllll}0.1 & 0.2 & 0.3 & 0.4 & 0.5 & 0.6 & 0.7 & 0.8 & 0.9\end{array}$

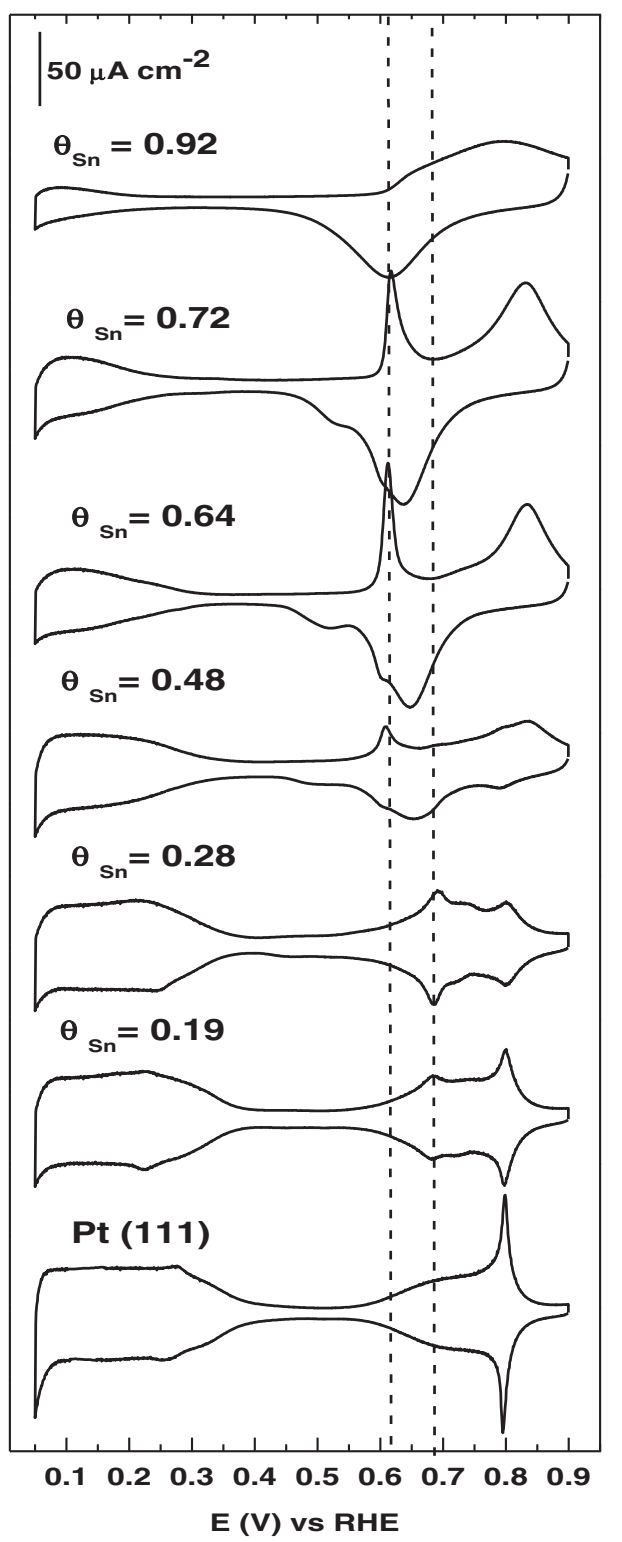

Fig. 1. Cyclic voltammograms of $\mathrm{Pt}(111)$ and $\mathrm{Sn} / \mathrm{Pt}(111)$ electrodes in $0.1 \mathrm{M} \mathrm{HClO}_{4}$; sweep rate $50 \mathrm{mV} \mathrm{s}^{-1}$.

$\mathrm{Sn}^{4+}$, and a one-electron process, such as $\mathrm{OH}$ adsorption, for the peak at $0.62 \mathrm{~V}$, in agreement with previous suggestions $[40,44]$. The desorption of the $\mathrm{OH}$ from platinum in the negative-going scan appears to overlap with the reduction of oxidized $\mathrm{Sn}$ adatoms in a broad peak in the region between 0.50 and $0.70 \mathrm{~V}$. If the Sn coverage is larger than 0.80 , only a broad current peak due to the oxidation (from 0.60 to $0.90 \mathrm{~V}$ in the positive-going scan) and reduction (from 0.75 to $0.50 \mathrm{~V}$ in the negative-going scan) of the Sn adatom, is observed. In order to estimate the surface stoichiometry for the adatom surface reaction, Feliu et al. found in previous work with other adatoms [45] that the relationship between the Pt charge density $\left(q_{P t}\right)$, which involves hydrogen plus $\mathrm{OH}$ adsorption, and the charge density associated with the adatom redox process (in this case $q_{s n}$ ), provides information about the stoichiometry of the adatom reaction. The quantity $q_{P t}$ is the sum of hydrogen and anion adsorption processes on the Pt sites (given the Sn coverage $\theta)$ :

$q_{P t}^{\theta}=q_{H}^{\theta}+q_{O H}^{\theta}$ 
The charge corresponding to hydrogen adsorption on the free $\mathrm{Pt}$ sites is given by:

$q_{H}^{\theta}=q_{H}^{\theta=0}(1-m \theta)$

Similarly, the charge corresponding to $\mathrm{OH}$ adsorption is given by:

$q_{\mathrm{OH}}^{\theta}=q_{\mathrm{OH}}^{\theta=0}(1-m \theta)$

where $q_{\mathrm{OH}}^{\theta=0}$ and $q_{\mathrm{H}}^{\theta=0}$ are the $\mathrm{OH}$ and hydrogen adsorption charge densities on the unmodified $\operatorname{Pt}(111), q_{H}^{\theta}$ and $q_{\mathrm{OH}}^{\theta}$ are the hydrogen and the $\mathrm{OH}$ adsorption charge densities on $\mathrm{Sn} / \mathrm{Pt}(111)$ for a given Sn coverage $\theta$, respectively, and $m$ is the number of Pt sites blocked by $1 \mathrm{Sn}$ atom (assuming $m$ is the same for $\mathrm{H}$ and $\mathrm{OH}$ ).

However, it is important to note that the adatom oxidation and $\mathrm{OH}$ adsorption on the free Pt sites overlap. Consequently, a refinement to the analysis would be to calculate $q_{\mathrm{OH}}^{\theta} \overline{\bar{H}}$ according to:

$q_{\mathrm{OH}}^{\theta}=q_{\mathrm{OH}}^{\theta=0} \frac{q_{H}^{\theta}}{q_{H}^{\theta=0}}$

The charge density associated with the oxidation of adsorbed Sn, $q_{S n}$, can be calculated by subtracting $q_{\mathrm{OH}}^{\theta}$ from the total charge density measured in between 0.45 and $0.90 \mathrm{~V}\left(q_{\mathrm{OH}+\mathrm{Sn}}^{\theta}\right)$ [46]:

$q_{S n}^{\theta}=q_{O H+S n}^{\theta}-q_{O H}^{\theta=0} \frac{q_{H}^{\theta}}{q_{H}^{\theta=0}}$

Fig. 2 shows the relation between $q_{P t}^{\theta}$ and $q_{S n}^{\theta}$. From the slope of the curve the relation between the numbers of blocked platinum sites with respect to the electrons exchanged per adsorbed Sn adatom can be calculated. In this case the value of the slope is around -0.83 . Therefore, assuming that 4 electrons are involved in the oxidation of the adatom (assuming the surface reaction $\mathrm{Sn}+4 \mathrm{H}_{2} \mathrm{O} \leftrightarrow \mathrm{Sn}(\mathrm{OH})_{4}+$ $\left.4 \mathrm{H}^{+}+4 \mathrm{e}^{-}\right)$, it is estimated that each $\mathrm{Sn}$ adatom blocks $3 \mathrm{Pt}(111)$ sites, suggesting that $\mathrm{Sn}$ adsorbs in three-fold hollow sites in a $(\sqrt{ }$ $3 \times \sqrt{3}) \mathrm{R} 30^{\circ}$ structure, in agreement with suggestions made by previous work [47].

The effect of the irreversible adsorption of Sn on the oxidation of adsorbed $\mathrm{CO}$ is shown in Fig. 3. CO stripping on the unmodified $\mathrm{Pt}(111)$ (Fig. 3a) electrode occurs in one sharp oxidation peak at $0.74 \mathrm{~V}$ and a small pre-peak at around $0.65 \mathrm{~V}$. The presence of this pre-peak is well documented in the literature, attributed to the oxidation of adsorbed $\mathrm{CO}$ by reaction with oxygenated species adsorbed at steps and defect sites [48].

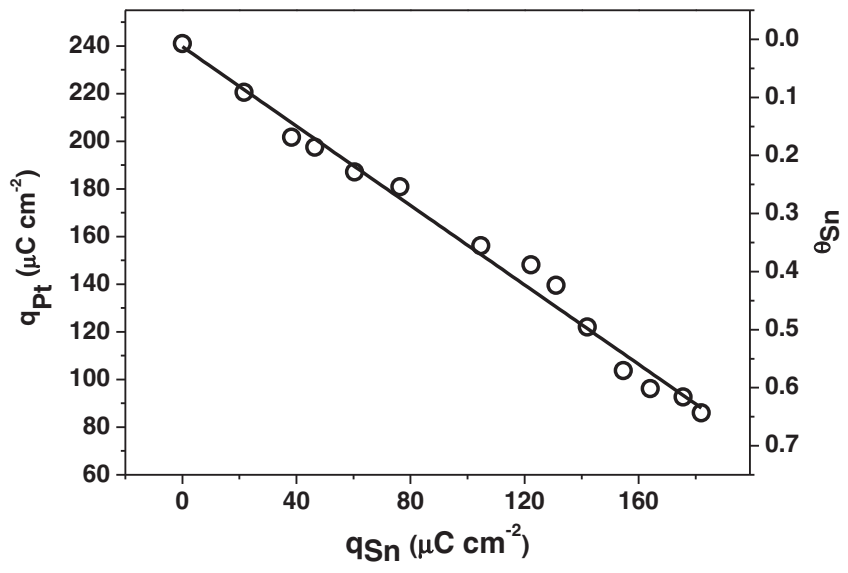

Fig. 2. Plot of the platinum surface charge density (as defined by Eq. (1)) and the corresponding Sn coverage vs. the charge density associated with $\mathrm{Sn}$ redox process on a $\mathrm{Pt}(111)$ electrode in $0.1 \mathrm{M} \mathrm{HClO}_{4}$ solution.

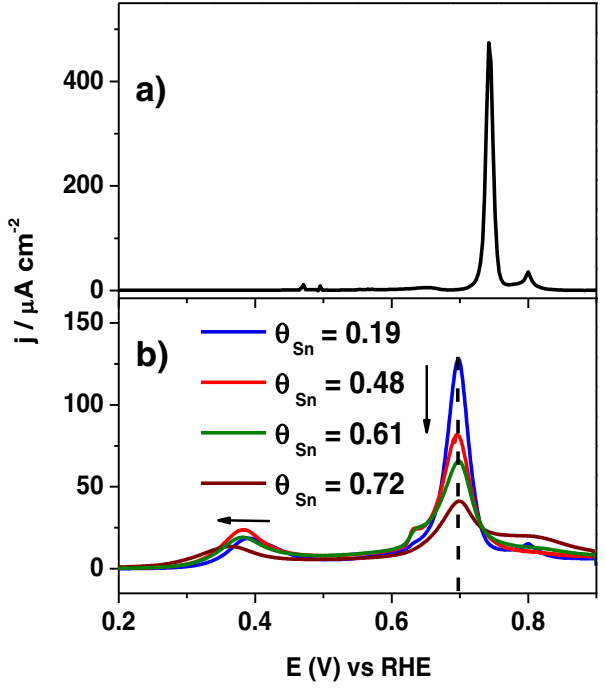

Fig. 3. Cyclic voltammograms of the CO oxidation on $\mathrm{Pt}(111)$ (a) and $\mathrm{Sn} / \mathrm{Pt}(111)$ electrodes (b) in $0.1 \mathrm{M} \mathrm{HClO}_{4}$; sweep rate $20 \mathrm{mV} \mathrm{s}^{-1}$.

The catalytic enhancement of the activity of the Pt electrode for CO oxidation by the irreversible adsorption of $\mathrm{Sn}$, as characterized by a lower potential for the CO stripping peak, is illustrated in Fig. 3b. On the $\mathrm{Sn} / \mathrm{Pt}(111)$ electrode, $\mathrm{CO}$ oxidation occurs in two distinct potential regions: the region above $0.50 \mathrm{~V}$, which includes the main $\mathrm{CO}$ oxidation peak at $0.69 \mathrm{~V}$, and the region below $0.50 \mathrm{~V}$ which we will call the prepeak whose position in the voltammogram depends on Sn coverage. The onset for the main $\mathrm{CO}$ oxidation peak takes place at approximately $0.60 \mathrm{~V}$, corresponding to the onset for $\mathrm{OH}$ adsorption on $\mathrm{Sn} / \mathrm{Pt}(111)$ surface (peak at $0.62 \mathrm{~V}$ in Fig. 1 ). Thus, this peak may be assigned to CO oxidation by adsorbed $\mathrm{OH}$ through a bifunctional mechanism and then the enhancement in the activity for CO oxidation on $\mathrm{Sn} / \mathrm{Pt}(111)$ electrodes can be explained by the fact that $\mathrm{Sn}$ atoms enable the electrochemical dissociation of water at more negative potentials compared with pure $\mathrm{Pt}(111)$

On the other hand, the nature of the pre-peak is more difficult to explain. The pre-peak takes place at potentials below $0.50 \mathrm{~V}$, where the voltammetry does not give any indication for the formation of $\mathrm{OH}$. Moreover, the pre-peak shifts to more negative potentials with increasing Sn coverage (see Fig. 4a), which may be rationalized by the fact that smaller CO islands are forming giving rise to a more weakly bonded state of $\mathrm{CO}$ due to a higher number of $\mathrm{CO}$ adsorbed on Pt sites adjacent to Sn atoms.

Fig. 4b shows the charge corresponding to the two peaks as a function of Sn coverage. Whereas the charge corresponding to the high-potential peak decreases with Sn coverage, suggesting that this CO is oxidized at "free" Pt sites, the charge corresponding to the pre-peak appears to exhibit a maximum with Sn coverage. This would be in agreement with the idea that the pre-peak is associated with CO oxidation at the interface between Pt and Sn sites, because with increasing Sn coverage the number of $\mathrm{CO}$ molecules adsorbed on Pt adjacent to Sn atoms increases because the higher number of Pt surrounded by Sn. However, at high Sn coverage there are fewer Pt sites left for CO to adsorb, leading to a maximum in the charge corresponding to the pre-peak. The exact nature of this low-potential $\mathrm{CO}_{\mathrm{ad}}$ oxidation remains somewhat speculative. The FTIR measurements by Stamenkovic et al. [38] and the DFT calculations by Dupont et al. [49] suggest that CO binds weaker to Pt near Sn sites in a $\mathrm{Pt}_{3} \mathrm{Sn}$ alloy surface. Other DFT calculations $[9,50]$ show that $\mathrm{OH}$ binds stronger to $\mathrm{Sn}$ than Pt sites, though we have not been able to resolve experimentally this low-potential $\mathrm{OH}$ formation on our Sn-modified Pt surfaces. In a theoretical work by Anderson, the CO oxidation in the pre-peak has been explained by oxidation at the edges of Sn surface islands, i.e., at Pt atoms in between Sn atoms, by a mechanism 
a)

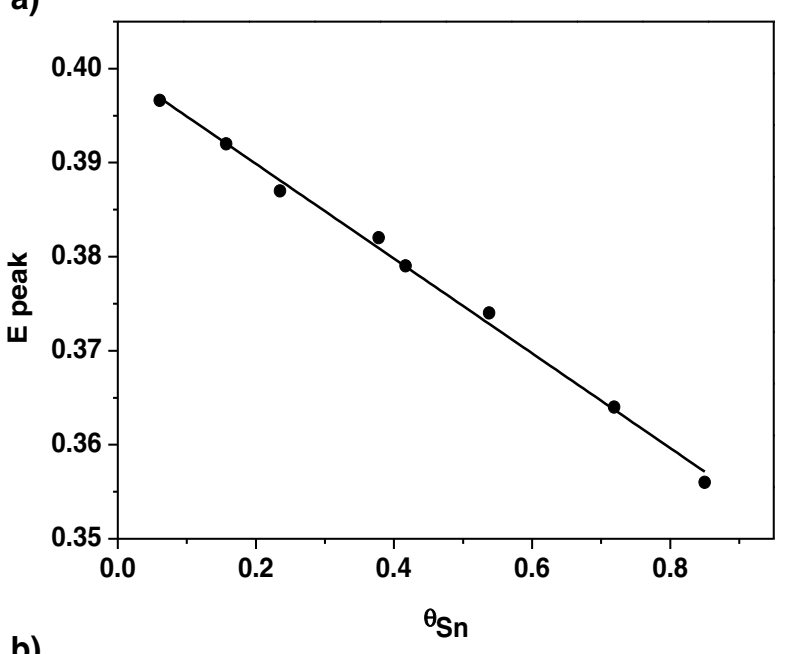

b)

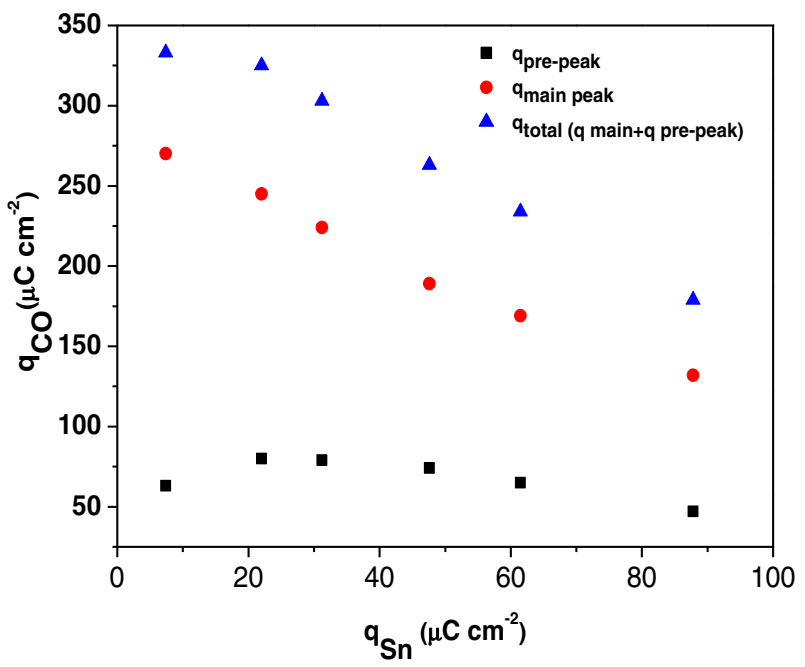

Fig. 4. Peak potential of the pre-peak (a) and CO charge (b) as a function of the Sncoverage on the $\mathrm{Sn} / \mathrm{Pt}(111)$ electrode in $0.1 \mathrm{M} \mathrm{HClO}_{4}$. Values received by CO-oxidation voltammetries as shown in Fig. 3.

of direct attack by $\mathrm{H}_{2} \mathrm{O}$ molecules [51]. An important aspect to point out is that the charge corresponding to the platinum states and the Sn oxidation peak are the same before $\mathrm{CO}$ adsorption and after $\mathrm{CO}$ oxidation, which indicates that $\mathrm{CO}$ does not induce the adatom desorption.

\section{2. $\operatorname{Pt}(100)$}

Fig. 5 shows the blank voltammetric profiles for Pt(100) and $\mathrm{Sn} /$ $\mathrm{Pt}(100)$ in $0.1 \mathrm{M} \mathrm{HClO}_{4}$. The profile for the unmodified Pt electrode is typical of a well-ordered Pt (100) surface and is delineated into various regions according to the electrosorption process. The hydrogen adsorption region occurs from 0.15 to $0.40 \mathrm{~V}$ which consist of two states at approximately 0.30 and $0.40 \mathrm{~V}$, although there is an overlap with a broad feature extending to about $0.60 \mathrm{~V}$, associated with $\mathrm{OH}$ adsorption [52]. At potentials higher than $0.75 \mathrm{~V}$ the oxidation of the $\mathrm{Pt}(100)$ surface begins, associated with the formation of platinum oxide species [53], which is almost negligible in the potential range chosen here. With increasing Sn coverage, a suppression of the hydrogen adsorption charge is observed together with the development of a new peak in the region between 0.70 and $0.90 \mathrm{~V}$ in the positive-going scan and between 0.80 and $0.55 \mathrm{~V}$ in the negative-going scan. These features are attributed to the oxidation of Sn adatoms, which takes place simultaneously with the formation of platinum oxide. It is important to consider that the

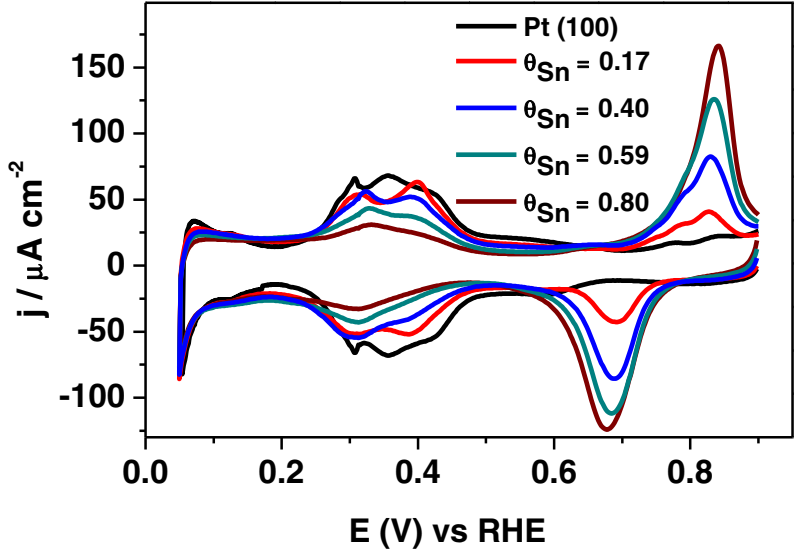

Fig. 5. Cyclic voltammograms of $\mathrm{Pt}(100)$ and $\mathrm{Sn} / \mathrm{Pt}(100)$ electrodes in $0.1 \mathrm{M} \mathrm{HClO}_{4}$; sweep rate $50 \mathrm{mV} \mathrm{s}^{-1}$

peaks due to $\mathrm{OH}$ adsorption observed on $\mathrm{Sn} / \mathrm{Pt}(111)$ are not observed (or not easily discerned) on $\mathrm{Sn} / \mathrm{Pt}(100)$ in the same potential range.

The surface stoichiometry for the adatom surface reaction on $\mathrm{Pt}(100)$ has been calculated in the same way as for Pt(111), although in this case no overlap exists between $\mathrm{Sn}$ oxidation and $\mathrm{OH}$ adsorption on Pt and the formation of Pt oxide in this potential range is almost negligible. Fig. 6 shows the linear correlation between Pt charge density (determined between 0.15 and $0.6 \mathrm{~V}$ ) and the charge density associated with the $S n$ redox process. The slope of the curve is -0.5 . Assuming the transfer of 4 electrons in the adatom oxidation process, as was considered for $\mathrm{Pt}(111)$, this slope suggest that each Sn adatom blocks 2 $\mathrm{Pt}(100)$ sites, and consequently, Sn may be adsorbed in four-fold hollow sites in a c $(2 \times 2)$ structure, in agreement with suggestions made in a previous study [41].

Fig. 7 displays the profiles for the oxidative stripping of adsorbed $\mathrm{CO}$ on $\mathrm{Pt}(100)$ and $\mathrm{Sn} / \mathrm{Pt}(100)$ electrodes. The oxidation of $\mathrm{CO}$ on $\mathrm{Pt}(100)$ electrode takes place in a single sharp peak at $0.76 \mathrm{~V}$. In the presence of Sn on the Pt(100) surface, the oxidation of CO also occurs in one sharp peak, at lower potentials compared to clean $\mathrm{Pt}(100)$, with the peak potential becoming lower with increasing Sn coverage. The prepeak observed on $\mathrm{Sn} / \mathrm{Pt}(111)$ is not present on $\mathrm{Sn} / \mathrm{Pt}(100)$. This enhancement in the activity of the electrode for $\mathrm{CO}$ oxidation on $\mathrm{Pt}(100)$ with Sn adsorption can be linked to a bifunctional mechanism through adatom oxidation since the onset potential for the oxidation of both

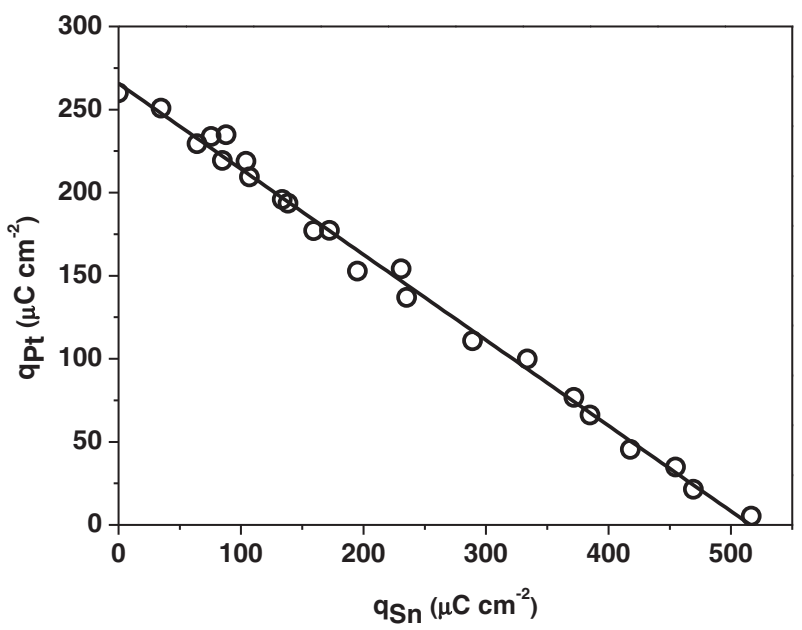

Fig. 6. Plot of the platinum surface charge density (as defined by Eq. (1)) and the corresponding Sn coverage vs. the charge density associated with $\mathrm{Sn}$ redox process on a $\mathrm{Pt}(100)$ electrode in $0.1 \mathrm{M} \mathrm{HClO}_{4}$ solution. 


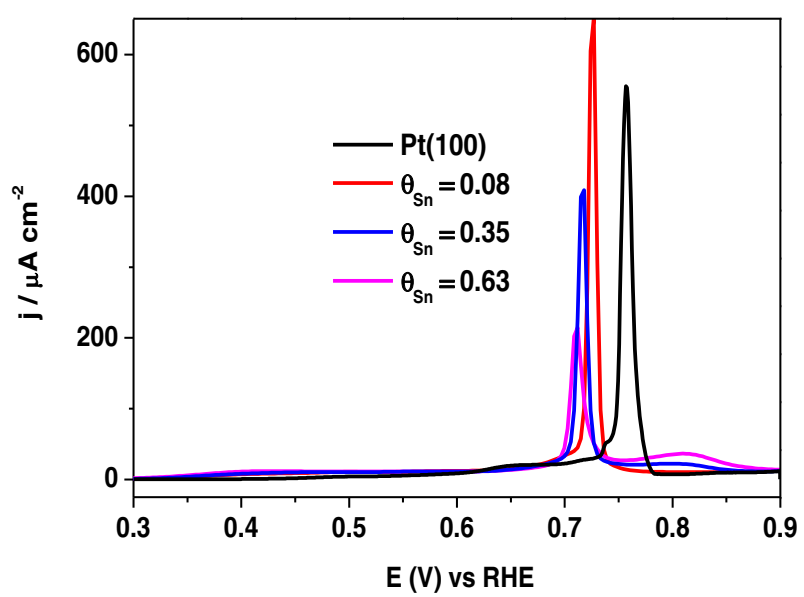

Fig. 7. Cyclic voltammograms of the $\mathrm{CO}$ oxidation on $\mathrm{Pt}(100)$ and $\mathrm{Sn} / \mathrm{Pt}(100)$ electrodes in $0.1 \mathrm{M} \mathrm{HClO}_{4}$; sweep rate $20 \mathrm{mV} \mathrm{s}^{-1}$.

$\mathrm{CO}$ and the Sn adatom, takes place at a very similar potential. Once Sn starts to oxidize, a fast stripping of the $\mathrm{CO}$ adlayer occurs simultaneously. Finally, the Sn adlayer on Sn/Pt(100) remains unmodified after the CO stripping experiment, as indicated by the identical blank CVs before and after stripping.

\section{3. $\operatorname{Pt}(110)$}

The blank cyclic voltammetric features for the unmodified $\operatorname{Pt}(110)$ and the Sn/Pt(110) surface are shown in Fig. 8. The hydrogen adsorption region, between 0.10 and $0.35 \mathrm{~V}$, consist of two states at 0.15 and $0.25 \mathrm{~V}$. The charge in this region is not only due to adsorption and desorption of hydrogen, but also to the replacement of adsorbed $\mathrm{H}$ with adsorbed $\mathrm{O}$ and/or $\mathrm{OH}$ [54]. In contrast to a previous work [41], in our experiments we were able to achieve the irreversible adsorption of Sn on $\mathrm{Pt}(110)$. This divergence with ref. 41 may be due to differences in the cooling process after flame-annealing of the electrode, as can be noted from the different shapes of the $\mathrm{Pt}(110)$ blank CV profiles. It is known that an appropriate cooling in $\mathrm{Ar}+\mathrm{H}_{2}$ stream produces a $\mathrm{Pt}(110)-(1 \times 2)$ surface phase, characterized by two peaks between 0 and $0.40 \mathrm{~V}$ [55]. However, the Pt(110) profile in ref. [41] does not show two different states in the same potential region, suggesting a different platinum surface. Like with $\mathrm{Pt}(111)$ and $\mathrm{Pt}(100)$, the adsorption of Sn on $\mathrm{Pt}(110)$ $(1 \times 2)$ leads to a decrease of the adsorption hydrogen charge and to a new peak due to the oxidation of Sn adatoms. The broad Sn redox

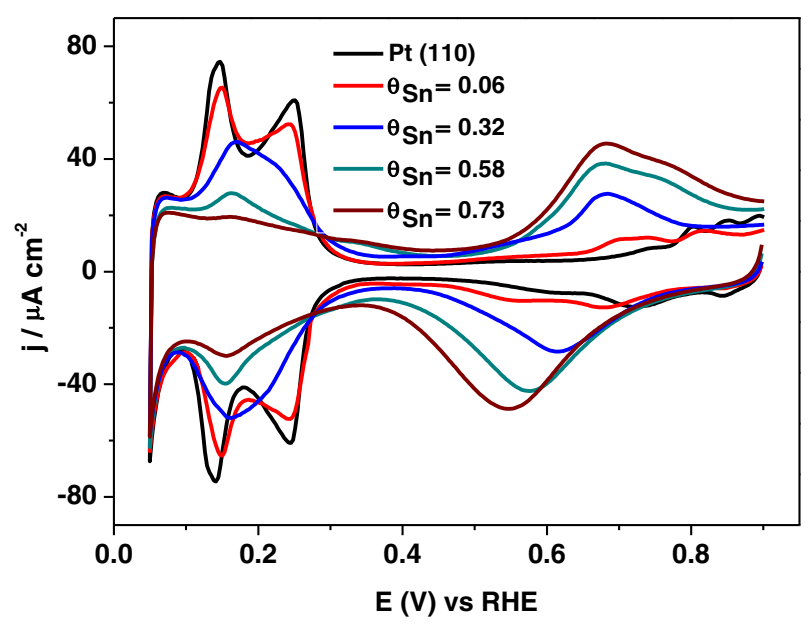

Fig. 8. Cyclic voltammograms of $\mathrm{Pt}(110)$ and $\mathrm{Sn} / \mathrm{Pt}(110)$ electrodes in $0.1 \mathrm{M} \mathrm{HClO}_{4}$; sweep rate $50 \mathrm{mV} \mathrm{s}^{-1}$. peak is centered at $0.70 \mathrm{~V}$ in the positive-going scan, and it becomes more irreversible with increasing Sn coverage with a shift to more negative potentials in the negative-going scan.

The surface stoichiometry for the adatom reaction on $\mathrm{Pt}(110)$ has been also obtained (Fig. 9). The slope of the curve is ca. -1 , which implies that either $4 \mathrm{e}^{-}$are involved in the oxidation of the adatom from $\mathrm{Sn}^{0}$ to $\mathrm{Sn}^{4+}$, or $2 \mathrm{e}^{-}$are involved from $\mathrm{Sn}^{0}$ to $\mathrm{Sn}^{2+}$. In the first case $\left(4 \mathrm{e}^{-}\right.$), the slope suggests that each $\mathrm{Sn}$ adatom blocks 4 Pt atoms (coverage of $0.25 \mathrm{ML}$ ), and in the second case $\left(2 \mathrm{e}^{-}\right)$, each Sn adatom blocks 2 Pt atoms (coverage of $0.5 \mathrm{ML}$ ). To be consistent with the Sn adatom charge on Pt(111) and Pt(100), the 0.25 ML coverage seems more likely.

Fig. 10 shows the CO oxidative stripping profiles on $\mathrm{Pt}(110)$ and $\mathrm{Sn} /$ $\mathrm{Pt}(110)$. The oxidation on $\mathrm{Pt}(110)$ takes place in a single sharp peak with a peak potential at $0.66 \mathrm{~V}$. As with $\mathrm{Sn} / \mathrm{Pt}(111)$ and $\mathrm{Sn} / \mathrm{Pt}(100)$, the blank cyclic voltammetry after the CO stripping experiment is the same as before $\mathrm{CO}$ stripping and, therefore, the adsorption of $\mathrm{CO}$ does not lead to the desorption of the adatom.

Modification of the electrode with Sn leads to significant changes in the CO oxidation profiles. Similar to Sn/Pt(111), two different CO oxidation regions can be observed: one pre-peak at low potentials and one main peak at higher potentials, which shift to more negative potentials with increasing Sn coverage. Moreover, the oxidation of the adatom takes place at potentials higher than that for $\mathrm{CO}$ oxidation which suggest that $S n$ does not act as a bifunctional catalyst but rather modifies the electronic properties of the Pt surface. In contrast to Pt(111) and $\mathrm{Pt}(100)$, the CO oxidation peak on Sn-modified Pt(110) is very broad and extends to potentials higher than the peak on unmodified $\operatorname{Pt}(110)$.

On the other hand, the nature of the pre-peak seems to be similar to the pre-peak on Pt(111), since it shows a shift to more negative potentials with increasing Sn coverage. The dependence of the charge of the two peaks on Sn coverage is shown in Fig. 11. The plot shows that the amount of $\mathrm{CO}$ oxidized in the pre-peak exhibits a maximum with $\mathrm{Sn}$ coverage, whereas that oxidized in the main peak decreases. It suggests that, similar to $\mathrm{Sn} / \mathrm{Pt}(111)$, the $\mathrm{CO}$ oxidation in the main peak is due to CO adsorbed at "free" Pt sites while the pre-peak is associated with CO oxidation at Pt atoms vicinal to Sn atoms.

\section{Conclusions}

In this work we have demonstrated that Sn can be adsorbed irreversibly on all three basal planes of platinum and this adsorption is sensitive to the surface structure of Pt single crystals. On all modified surfaces, the presence of $\mathrm{Sn}$ blocks the adsorption of hydrogen on platinum, and leads to the observation of a new oxidation peak ascribed to

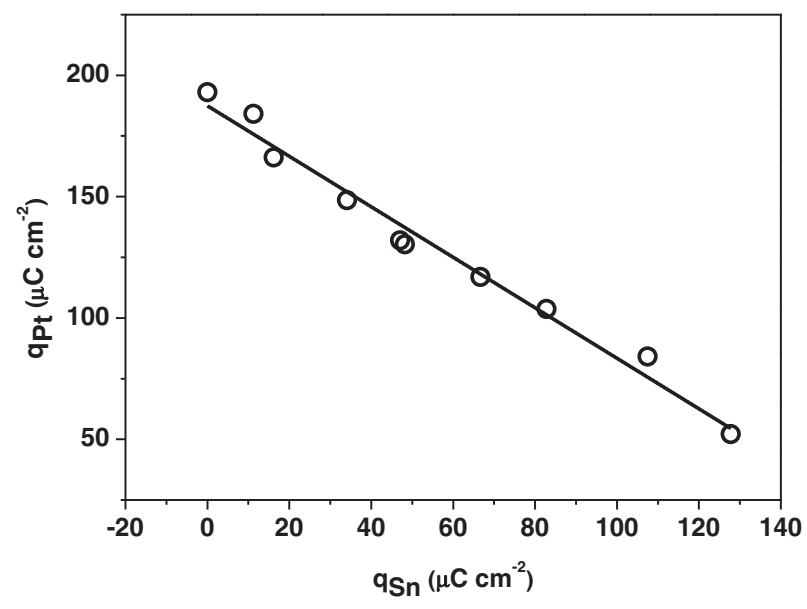

Fig. 9. Plot of the platinum surface charge density (as defined by Eq. (1)) and the corresponding Sn coverage vs. the charge density associated with Sn redox process on a $\mathrm{Pt}(110)$ electrode in $0.1 \mathrm{M} \mathrm{HClO}_{4}$ solution. 


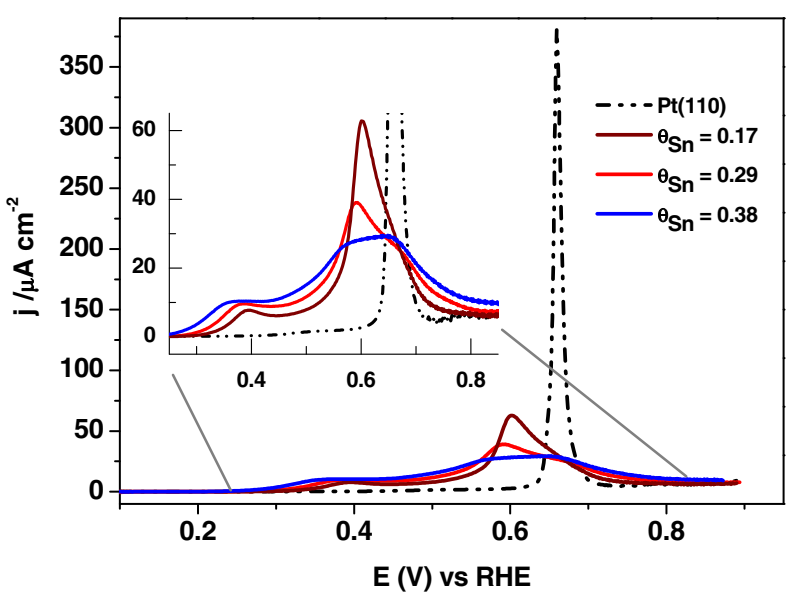

Fig. 10. Cyclic voltammograms of the $\mathrm{CO}$ oxidation on $\mathrm{Pt}(110)$ and $\mathrm{Sn} / \mathrm{Pt}(100)$ electrodes in $0.1 \mathrm{M} \mathrm{HClO}_{4}$; sweep rate $20 \mathrm{mV} \mathrm{s}^{-1}$.

the four-electron oxidation of the Sn adatom. On Pt(111), this adatom oxidation happens near $0.6 \mathrm{~V}$ (Vs. RHE), on Pt(100) at 0.7-0.8 V, and on $\mathrm{Pt}(110)$ from ca. $0.5 \mathrm{~V}$. From the CVs, the estimated maximum $\mathrm{Sn}$ coverage is 0.33 (per surface Pt atom) on Pt(111) and 0.50 (per surface Pt atom) on Pt(100), whereas for Pt(110) the surface stoichiometry for the adatom surface reaction is not fully clear but most likely corresponds to $0.25 \mathrm{ML}$ (per surface Pt atom).

The results obtained for $\mathrm{CO}_{\mathrm{ad}}$ oxidation on $\mathrm{Sn} / \mathrm{Pt}(111), \mathrm{Sn} / \mathrm{Pt}(100)$ and $\mathrm{Sn} / \mathrm{Pt}(110)$ demonstrated that the irreversible adsorption of Sn enhances the electroactivity for this reaction on all three Pt single crystals. On Sn/Pt(111) and Sn/Pt(110), oxidation of adsorbed CO occurs in two distinct potential regions: a pre-peak region at potentials below $0.50 \mathrm{~V}$ and the main peak at potentials higher than $0.50 \mathrm{~V}$. From the dependence of the charge of the pre-peak on the Sn coverage, we conclude that for the former potential window, the oxidation of adsorbed $\mathrm{CO}$ takes place at the direct interface between Pt and Sn through the formation of an activated water species on Sn that is not observable in the blank voltammetry. In the main peak, the $\mathrm{CO}_{\mathrm{ad}}$ oxidation reaction is

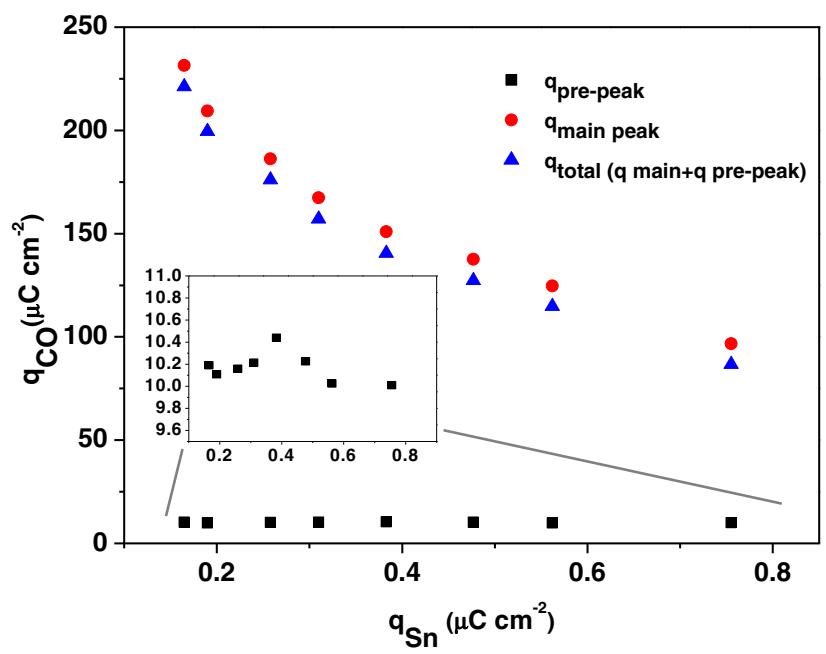

Fig. 11. CO charge as a function of the tin-coverage on the $\mathrm{Sn} / \mathrm{Pt}(110)$ electrode in $0.1 \mathrm{M}$ $\mathrm{HClO}_{4}$. Values for the charges obtained by integrating the corresponding $\mathrm{CO}$ oxidation peak in the voltammetries as shown in Fig. 10. The charge for the CO oxidation in the pre-peak and the main peak were calculated by subtraction of a capacitive background charge estimated as a linear background between the onset potential of $\mathrm{CO}$ oxidation in the pre-peak and the onset of the main CO oxidation peak, and from the onset of the main peak to $0.90 \mathrm{~V}$ vs. RHE, respectively. suggested to occur through the classical bifunctional mechanism of $\mathrm{OH}$ adsorbed on Sn with $\mathrm{CO}$ adsorbed on Pt atoms that are not in direct contact with $\mathrm{Sn}$ adatoms that is, on Pt atoms no adjacent to Sn atoms. On the contrary, the "pre-peak mechanism" is not observed on Sn/Pt(100).

\section{Acknowledgement}

R.R. is indebted to MINECO for the pre-doctoral grant in the project CTQ2011-28913-C02-02.

\section{References}

[1] J.J. Baschuk, X. Li, Int. J. Energy Res. 25 (2001) 695.

[2] J. Asgardi, J.C. Calderón, F. Alcaide, A. Querejeta, L. Calvillo, M.J. Lázaro, G. García, E. Pastor, Appl. Catal. B Environ. 168-169 (2015) 33.

[3] T. Okanishi, T. Matsui, T. Takeguchi, R. Kikuchi, K. Eguchi, Appl. Catal. A Gen. 298 (2006) 181.

[4] K. Grass, H. Lintz, J. Catal. 452 (1997) 446.

[5] R. Rizo, D. Sebastián, M.J. Lázaro, E. Pastor, Appl. Catal. B 200 (2017) 246.

[6] R. Rizo, M.J. Lázaro, E. Pastor, M.T.M. Koper, Chem. Electro. Chem. (2016), http://dx. doi.org/10.1002/celc.201600438.

[7] R. Rizo, M.J. Lázaro, E. Pastor, G. García, Molecules 21 (2016) 1225.

[8] S. Stevanović, D. Tripković, V. Tripkovic, D. Minić, A. Gavrilović, A. Tripković, V.M. Jovanović, J. Phys. Chem. C 118 (2013) 278.

[9] V. Tripkovic, Electrochim. Acta 168 (2015) 370.

[10] F. McBride, G.R. Darling, K. Pussi, C.A. Lucas, Y. Grunder, M. Darlington, A. Hodgson, J. Phys. Chem. C 117 (2013) 4032

[11] N.P. Lebedeva, M.T.M. Koper, E. Herrero, J.M. Feliu, R.A. Van Santen, J. Electroanal. Chem. 487 (2000) 37.

[12] G. García, M.T.M. Koper, Phys. Chem. Chem. Phys. 10 (2008) 3802.

[13] G. García, M.T.M. Koper, Chem. Phys. Chem. 12 (2011) 2064.

[14] R. Gisbert, G. García, M.T.M. Koper, Electrochim. Acta 56 (2011) 2443.

[15] J. Solla-Gullón, F.J. Vidal-Iglesias, E. Herrero, J.M. Feliu, A. Aldaz, Electrochem. Commun. 8 (2006) 189.

[16] N.P. Lebedeva, M.T.M. Koper, J.M. Feliu, R.A. Van Santen, J. Phys. Chem. B 106 (2002) 12938.

[17] N.P. Lebedeva, A. Rodes, J.M. Feliu, M.T.M. Koper, R.A. Van Santen, J. Phys. Chem. B 106 (2002) 9863.

[18] T.J. Schmidt, P.N. Ross, N.M. Markovic, J. Phys. Chem. B 105 (2001) 12082.

[19] J.M. Feliu, J.M. Orts, A. Femandez-Vega, A. Aldaz, J. Clavilier, J. Electroanal. Chem. 296 (1990) 191-201.

[20] M. Eiswirth, P. Möller, K. Wetzl, R. Imbihl, G. Ertl, J. Chem. Phys. 90 (1989) 510.

[21] C. Lamy, J.M. Leger, J. Clavilier, R. Parsons, J. Electroanal. Chem. 150 (1983) 71-77.

[22] Q.S. Chen, A. Berna, V. Climent, S.G. Sun, J.M. Feliu, Phys. Chem. Chem. Phys. 12 (2010) 11407

[23] N.M. Marković, C.A. Lucas, A. Rodes, V. Stamenković, P.N. Ross, Surf. Sci. 499 (2002) L149-L158.

[24] V. Stamenkovic, K.C. Chou, G.A. Somorjai, P.N. Ross, N.M. Markovic, J. Phys. Chem. B 109 (2005) 678-680.

[25] J. Clavilier, R. Albalat, R. Gomez, J.M. Orts, J.M. Feliu, A. Aldaz, J. Electroanal. Chem. 330 (1992) 489.

[26] N.P. Lebedeva, M.T.M. Koper, J.M. Feliu, R.A. van Santen, Electrochem. Commun. 2 (2000) 487.

[27] E. Herrero, B. Álvarez, J.M. Feliu, S. Blais, Z. Radovic-Hrapovic, G. Jerkiewicz, J. Electroanal, Chem 567 (2004) 139.

[28] G. Samjeské, K.I. Komatsu, M. Osawa, J. Phys. Chem. C 113 (2009) 10222.

[29] Y.Y. Yang, L.N. Zhang, M. Osawa, W.B. Cai, J. Phys. Chem. Lett. 4 (2013) 1582.

[30] V. Climent, E. Herrero, J.M. Feliu, Electrochim. Acta 44 (1998) 1403.

[31] E. Herrero, J.M. Feliu, A. Aldaz, J. Catal. 152 (1995) 264-274.

[32] V. Del Colle, J. Souza-Garcia, G. Tremiliosi-Filho, E. Herrero, J.M. Feliu, Phys. Chem. Chem. Phys. 13 (2011) 12163-12172.

[33] E. Herrero, A. Rodes, J.M. Pérez, J.M. Feliu, A. Aldaz, J. Electroanal. Chem. 412 (1996) $165-174$.

[34] W.F. Lin, M.S. Zei, M. Eiswirth, G. Ertl, T. Iwasita, W. Vielstich, J. Phys. Chem. B 103 (1999) 6968.

[35] J.C. Davies, B.E. Hayden, D.J. Pegg, Electrochim. Acta 44 (1998) 1181

[36] J.S. Spendelow, P.K. Babu, A. Wieckowski, Curr. Opin. Solid St. M. 9 (2005) 37.

[37] B.E. Hayden, M.E. Rendall, O. South, J. Am. Chem. Soc. 125 (2003) 7738

[38] V.R. Stamenkovic, M. Arenz, C.A. Lucas, M.E. Gallagher, P.N. Ross, N.M. Markovic, J. Amer. Chem. Soc. 125 (2003) 2736.

[39] V. Stamenković, M. Arenz, B.B. Blizanac, K.J.J. Mayrhofer, P.N. Ross, N.M. Marković, Surf. Sci. 576 (2005) 145

[40] H. Massong, S. Tillmann, T. Langkau, E.A. El Meguid, H. Baltruschat, Electrochim. Acta 44 (1998) 1379.

[41] Q.W. Zheng, C.J. Fan, C.H. Zhen, Z.Y. Zhou, S.G. Sun, Electrochim. Acta 53 (2008) 6081

[42] J. Clavilier, D. Armand, S.G. Sun, M. Petit, J. Electroanal. Chem. 205 (1986) 267.

[43] A. El-Shafei, M. Eiswirth, Surf. Sci. 604 (2010) 862.

[44] X.Y. Xiao, S. Tillmann, H. Baltruschat, Phys. Chem. Chem. Phys. 4 (2002) 4044

[45] V. Climent, N. García-Aráez, J.M. Feliu, Fuel Cell Catalysis: A Surface Science Approach, 2009209.

[46] V. Climent, N. Garcia-Araez, R.G. Compton, J.M. Feliu, J. Phys. Chem. B 110 (2006) 21092.

[47] A.N. Haner, P.N. Ross, J. Phys. Chem. 95 (1991) 3740.

[48] A. López-Cudero, A. Cuesta, C. Gutiérrez, J. Electroanal. Chem. 579 (2005) 1. 
[49] C. Dupont, Y. Jugnet, D. Loffreda, J. Am. Chem. Soc. 128 (2006) 9129.

[50] T.E. Shubina, M.T.M. Koper, Electrochim. Acta 47 (2002) 3621.

[51] E. Grantscharova-Anderson, A.B. Anderson, Electrochem. Acta. 44 (1999) 4543.

[52] G.A. Attard, A. Brew, K. Hunter, J. Sharman, E. Wright, Phys. Chem. Chem. Phys. 16 (2004) 13689.
[53] Y.-F. Huang, P.J. Kooyman, M.T.M. Koper, Nat. Commun. 7 (2016) 12440.

[54] M.J.T.C. Van der Niet, N. Garcia-Araez, J. Hernández, J.M. Feliu, M.T.M. Koper, Catal. Today 202 (2013) 105.

[55] G.A. Attard, A. Brew, J. Electroanal. Chem. 747 (2015) 123. 